Original Research Article

\title{
A comparative study to evaluate diagnostic agreement of IMNCI algorithm in young infants
}

\author{
Bansal R. ${ }^{1}$, Sharma R.K. ${ }^{2}$, Nayak M. ${ }^{3}$, Firoz S. ${ }^{4}$ \\ ${ }^{1}$ Dr. Rishi Bansal, Assistant Professor, ${ }^{2}$ Dr. Ram Kshitij Sharma, Lecturer, ${ }^{3}$ Dr. Madhu Nayak, Assistant Professor, \\ ${ }^{4}$ Dr. Shehraz Firoz, Assistant Professor, ${ }^{1,4}$ authors are affiliated with Department of Pediatrics, FH Medical College, Tundla, \\ Uttar Pradesh and ${ }^{2,3}$ authors are affiliated with Department of Pediatrics, S.N. Medical College, Agra, Uttar Pradesh, India.
}

Corresponding Author: Dr. Ram Kshitij Sharma, Lecturer, Department of Pediatrics, S.N. Medical College, Agra, Uttar Pradesh, India. E-mail: ramkshitijsharma@gmail.com

\begin{abstract}
Background: Under-five and infant mortality constitutes a major health problem in India. To combat this high mortality, IMCI strategy aiming at holistic and integrated approach to child health and development was developed by WHO. This study is a comparative study conducted at Emergency and Outpatient Department of Pediatrics FHMC Tundla and SNMC Agra. Total of 200 young infants (0-2months) were taken. Detailed history and examination was done for all enrolled young infants according to IMNCI and for enrolled infants diagnosis and treatment was made in the Pediatric Department and was considered as Gold Standard. Results: Out of total 200 young infants, 117 were 0-7 days of age and rest 83 were 7- 59 days of age. Of these 109 infants were admitted, and 91 infants were sent home after initial management. There was no mismatch in diagnosis of $48 \%$ infants, while partial mismatch in $38.5 \%$ infants, over diagnosis in $10.5 \%$ and under diagnosis was present in $3 \%$ infants of 0-2 months of age. Conclusion: This study had good diagnostic agreement and only $3 \%$ of infants were underdiagnosed.
\end{abstract}

Keywords: IMCI, Diagnostic Agreement, Childhood Illness, Integrated Management of Childhood Illness

\section{Introduction}

Globally, close to 10 million children including 4 million neonates die each year $[1,2,3,4,5]$. In response to this challenge, WHO and UNICEF in the early 1990s developed Integrated Management of Childhood Illness (IMCI), a strategy designed to reduce child mortality and morbidity in developing countries [6]. This strategy combines improved management of childhood illness with aspects of nutrition, immunization and other important disease prevention and health promotion elements $[7,8]$. However, before widespread implementation, the IMCI algorithms require careful evaluation to reflect the epidemiological and cultural characteristics of the country and adaptations as per the regional morbidity patterns $[9,10,11]$.

Under-five and infant mortality constituted a major health problem in India. To combat the challenge of high underfive mortality, IMCI strategy aiming at holistic and integrated approach to child health and development was developed by WHO, but it did not include the early neonatal period (0-7 days) due to programmatic reasons.

Manuscript received: $14^{\text {th }}$ November 2019

Reviewed: $24^{\text {th }}$ November 2019

Author Corrected: $30^{\text {th }}$ November 2019

Accepted for Publication: $5^{\text {th }}$ December 2019
This generic algorithm has been adapted to cover the 0-7 days age in India and is termed Integrated Management of Neonatal and Childhood Illness (IMNCI). Various studies from India and other developing countries have validated the IMCI algorithm in both 7 days -2 months and 2 months-5 years age groups [12-14]. The signs and symptoms of several of the major childhood illnesses contributing to under-five mortality have a substantial overlap.

Thus, a single diagnosis for a sick child is often inappropriate because it identifies only the most apparent problem and can lead to an associated and potentially lifethreatening problem being overlooked. For effective management of these major childhood illnesses, WHO and UNICEFF have developed the "Integrated Management of Childhood Illness" (IMCI) Strategy [15,16].

IMNCI aims to reduce death, illness and disability, and to promote improved growth and development among children under 5 years of age. IMNCI includes both preventive and curative elements that implemented by families and communities as well as by health facilities [17]. 


\section{Materials and Methods}

Study design: Comparative study.

Place: Emergency and Outpatient Department of Pediatrics FHMC Tundla and SNMC Agra

Study duration: One Year (Jan 2018 to Dec 2018)

Sample size: Total of 200 young infants were taken from Emergency and Outpatient Department of Pediatrics.

Inclusion criteria: Any infant presented with a fresh episode of any illness in the Emergency or the Outpatient Department of the Pediatrics in BPKIHS.

Exclusion criteria: Infants attended the well baby clinic or immunization clinic for routine visits.

\section{Methods}

Young infants presenting to OPD and Emergency of pediatrics for fresh illness were included in the study.
Detailed history and examination were done for all enrolled young infants and was recorded in proforma according to IMNCI and for enrolled infants diagnosis and treatment was made in the Pediatric Department and was considered as Gold Standard. All the relevant investigations were sent and treated accordingly in the department of pediatrics.

Statistical analysis: The data was evaluated in the predesigned proforma, data were entered into MS Excel and analyzed using SPSS 10.01 for window 7, chi square test and fisher's exact test, sensitivity, specificity, positive predictive value and negative predictive value.

The broad treatment agreement was compared using descriptive statistics and using statistical tests of significance wherever possible.

\section{Results}

In this study out of 200 young infants, 117 were $0-7$ days of age and rest 83 were 7 - 59 days of age as shown in Table 1.

Table-1: Age distribution of study infants.

\begin{tabular}{|c|c|c|}
\hline & Number & Percent (\%) \\
\hline $0-7$ days & 117 & $58.5 \%$ \\
\hline 7 days-2 months & 83 & $41.5 \%$ \\
\hline Total & 200 & $100 \%$ \\
\hline
\end{tabular}

Total of 200 young infants were included in the study, of which $61.5 \%$ were male and $38.5 \%$ were female infants as shown in Table 2.

Table-2: Sex distribution of study infants (0-2 months).

\begin{tabular}{|c|c|c|}
\hline & Number & Percent (\%) \\
\hline Male & 123 & $61.5 \%$ \\
\hline Female & 77 & $38.5 \%$ \\
\hline Total & 200 & $100 \%$ \\
\hline
\end{tabular}

There were $58.1 \%$ males and $41.9 \%$ females in age group $0-7$ days of age group as shown in Table 3 .

Table-3: Sex distribution of study infants (0-7days).

\begin{tabular}{|c|c|c|}
\hline & Number & Percent (\%) \\
\hline Male & 68 & $58.1 \%$ \\
\hline Female & 49 & $41.9 \%$ \\
\hline Total & 117 & $100 \%$ \\
\hline
\end{tabular}

There were $66.2 \%$ males and $33.8 \%$ females in infants 7 days to 2 months of age group as shown in Table 4 .

Table-4: Sex distribution of study infants (7days-2 months).

\begin{tabular}{|c|c|c|}
\hline & Number & Percent (\%) \\
\hline Male & 55 & $66.2 \%$ \\
\hline Female & 28 & $33.8 \%$ \\
\hline Total & 83 & $100 \%$ \\
\hline
\end{tabular}


A total of 100 infants were recruited each from the OPD and Emergency. Out of which 109 infants were admitted, and 91 infants were sent home after initial management as shown in Table 5.

Table-5: Relationship between recruitment and hospitalization (0-2months).

\begin{tabular}{|c|c|c|c|}
\hline & Admitted & Sent Home & Total \\
\hline OPD & 21 & 79 & 100 \\
\hline Emergency & 88 & 12 & 100 \\
\hline Total & 109 & 91 & 200 \\
\hline
\end{tabular}

There were total of 72 admissions, 4 from OPD and 68 form emergency and rest 45 were sent home in 0-7 days age group as shown in Table 6.

Table-6: Relationship between recruitment and hospitalization (0-7 days).

\begin{tabular}{|c|c|c|c|}
\hline & Admitted & Sent Home & Total \\
\hline OPD & 4 & 38 & 42 \\
\hline Emergency & 68 & 7 & 117 \\
\hline Total & 72 & 45 \\
\hline
\end{tabular}

There were 37 admission and rest 46 infants were sent home in 7days -2 months of age as shown in Table 7 .

Table-7: Relationship between recruitment and hospitalization (7-59 days).

\begin{tabular}{|c|c|c|c|}
\hline & Admitted & Sent Home & Total \\
\hline OPD & 17 & 41 & 58 \\
\hline Emergency & 20 & 5 & 25 \\
\hline Total & 37 & 46 & 83 \\
\hline
\end{tabular}

It was observed that out of 200 infants included in study, $21(10.5 \%)$ infants died and $179(89.5 \%)$ recovered and discharged from hospital.

In this study diagnostic agreement between the IMNCI and Gold standard were compared. Those infants which were referred with one or more diagnosis or sent home according to IMNCI and was admitted to hospital or sent home with same diagnosis was considered as No Mismatch. Those infants which were referred with one or more illnesses according to IMNCI and was admitted with difference in one or more diagnosis according to Gold Standard was considered as Partial Mismatch. Infants which were referred according to IMNCI module and was sent home according to Gold Standard was considered as Overdiagnosis. Those infants which were sent home according to IMNCI module and was admitted in hospital as per Gold Standard was considered as Underdiagnosis.

There was no mismatch in diagnosis in $48 \%$ infants while partial mismatch was present in $38.5 \%$ infants. Over diagnosis was present in $10.5 \%$ and under diagnosis was present in $3 \%$ of $0-2$ months of age young infants as shown in Table 8 .

Table-8: Diagnostic agreement between gold standard and IMNCI Algorithm (0-2 months).

\begin{tabular}{|c|c|c|}
\hline Type of mismatch & Number & Percentage (\%) \\
\hline No mismatch & 96 & $48 \%$ \\
\hline Partial mismatch & 77 & $38.5 \%$ \\
\hline Over-diagnosis & 21 & $10.5 \%$ \\
\hline Under-diagnosis & 6 & $3 \%$ \\
\hline Total & 200 & $100 \%$ \\
\hline
\end{tabular}

There was no mismatch in $45.3 \%$, partial mismatch in $36.7 \%$, over-diagnosis in $14.5 \%$ and under-diagnosis in $3.5 \%$ of infants in 0 - 7 days of age respectively as depicted in Table 9. 
Original Research Article

Table-9: Diagnosis agreement between gold standard and IMNCI algorithm (0-7 days).

\begin{tabular}{|c|c|c|}
\hline Type of mismatch & Number & Percentage (\%) \\
\hline No mismatch & 53 & $45.3 \%$ \\
\hline Partial mismatch & 43 & $36.7 \%$ \\
\hline Over-diagnosis & 17 & $14.5 \%$ \\
\hline Under-diagnosis & 4 & $3.5 \%$ \\
\hline Total & 117 & $100 \%$ \\
\hline
\end{tabular}

There was no mismatch in $51.8 \%$, partial mismatch in $41 \%$, over-diagnosis in $4.8 \%$ and under-diagnosis in $2.4 \%$ of infants in 0-7 days of age as depicted in Table 10 .

Table-10: Diagnostic agreement between gold standard and IMNCI Algorithm (7 days - 2 months).

\begin{tabular}{|c|c|c|}
\hline Type of mismatch & Number & Percentage (\%) \\
\hline No mismatch & 43 & $51.8 \%$ \\
\hline Partial mismatch & 34 & $41.0 \%$ \\
\hline Over-diagnosis & 4 & $4.8 \%$ \\
\hline Under-diagnosis & 2 & $2.4 \%$ \\
\hline Total & $\mathbf{8 3}$ & $\mathbf{1 0 0} \%$ \\
\hline
\end{tabular}

\section{Discussion}

A total of 200 infants between 0-2 months who fulfilled the study criteria were investigated. Of these $117(58.5 \%)$ were $0-7$ days of age and rest $83(41.5 \%)$ were 7 to 59 days of age. Similar study conducted by Kaur et al [18] showed that $42 \%$ infants were $0-7$ days and $58 \%$ infants were 7 days to 2 months of age which is almost similar to the present study.

In the current study, $61.5 \%$ infants were male and $38.5 \%$ infants were female. In this study total of $54.5 \%$ infants were admitted and rest $45.5 \%$ were sent home. Admitted babies were significantly higher in Emergency group as compared to the OPD in $0-7$ days as $90.6 \%$ and $9.5 \%$ and 7-59 days was $80 \%$ and $29.3 \%$ respectively.

In similar study conducted by Kaur et al [18] admission from emergency and OPD in 0-7 days was 96.3\% and $85.4 \%$ and $7-59$ days were $97.5 \%$ and $38.6 \%$ respectively. Higher percentage of admission in this study may be due to difference in study settings but a greater number of admissions from emergency is comparable.

Similar study conducted by Goswami et al [14] showed that $66 \%$ of infants in early neonatal period (0-7 days) were admitted as compared to $52 \%$ in 7 days- 2 months age groups that was corresponding to the present study. Other study conducted by Gupta et al [13] showed that $65.7 \%$ of infants were admitted and rest $34.3 \%$ were sent back home in 7 days -2 months age groups.
In this study no mismatch or complete diagnostic agreement was present in nearly half (48\%) of infants, partial mismatch was there in $38.5 \%$ infants, overdiagnosis was present in $10.5 \%$ and underdiagnosis was present in $3 \%$ infants. Subdividing the data to $0-7$ days age group, complete agreement, partial mismatch, over diagnosis and under diagnosis was $45.3 \%, 36.7 \%, 14.5 \%, 3.5 \%$ - and 7 59-days age group was $51.8 \%, 41.0 \%, 4.8 \%, 2.4 \%$ respectively. Kaur et al [18] had complete diagnostic agreement, partial mismatch, overdiagnosis, underdiagnosis in $0-7$ days as $40.3 \%, 31.3 \%, 15.9 \%, 12.5 \%$ and 7- 59 days as $55.9 \%, 10.3 \%, 20.6 \%, 13.2 \%$ respectively. The diagnostic agreement percentage in this study was comparable to the present study.

Another study conducted by Goswami et al [14] showed that no mismatch, partial mismatch, overdiagnosis underdiagnosis was $57 \%, 42 \%, 16 \%, 87 \%$ in $0-7$ days age group and $68 \%, 32 \%, 72 \%, 29 \%$ in $7-59$ days age group respectively which is comparable. Gupta et al [13] conducted study in 7-59 days age group and showed that complete agreement was present in $60 \%$ young infants. Partial mismatch, overdiagnosis, underdiagnosis was $40 \%$, $21 \%$, and $22.5 \%$ respectively which is comparable to the present study.

Another study conducted by Bhattacharya et al [19] showed that IMNCI algorithm decisions were compared with the pediatrician's decisions and it was revealed that 
Original Research Article

the overall diagnostic agreement was $55.56 \%$, and among the disagreements, $33.33 \%$ was due to over diagnosis, and $11.11 \%$ was due to under diagnosis.

Another similar study by Thummakomma et al [20] which included 500 young infants showed that there was no mismatch in diagnosis in approximately $75 \%$ of study infants which is much more as compared to the present study.

Partial mismatch was present in $10 \%$ infants, under diagnosis in $8 \%$ infants, and overdiagnosis in $6 \%$ infants. Combination of no mismatch and partial mismatch is almost comparable to the present study.

Study Limitations- Although the gold standard diagnosis and treatment were done by the consultants in Pediatrics department but the IMNCI proforma filled by the researchers were not blinded. Hence, possibility of bias cannot be ruled out.

\section{Conclusion}

This study was done to compare IMNCI algorithm with the diagnosis of Pediatricians at a tertiary care centre in 0 2 moths age group. In this study out of total 200 infants, $54.5 \%$ were admitted and rest $45.5 \%$ were sent home. This study had no mismatch or complete diagnostic agreement $48 \%$ of infants, partial mismatch in $38.5 \%$ infants, overdiagnosis in $10.5 \%$ and underdiagnosis was present in only $3 \%$ infants.

\section{What this study adds to existing knowledge?}

IMNCI Algorithm had a good diagnostic agreement, only very few infants were underdiagnosed as compared to paediatrician diagnosis. Hence it is an important algorithm for the diagnosis of illnesses in young infants (0-2 months).

\section{Author's Contribution}

Dr. Rishi Bansal: Conceived the idea of study, did data collection, supervised the study, analysis of data and interpretation of results, participated in study design, write up the manuscript.

Dr. Ram Kshitij Sharma: Data collection, supervised the study, analysis of data and interpretation of results, reviewed related literature, and write up of manuscript.

Dr. Madhu Nayak: Reviewed related literature and write up of manuscript.

Dr. Shehraz Firoz: Reviewed related literature and write up of manuscript.
Funding: No funding sources

Conflict of interest: None declared

Ethical Approval: This study was approved by the Institutional Ethics Committee

\section{References}

1. Nicoll A. Integrated management of childhood illness in resource-poor countries: an initiative from the World Health Organization. Trans R Soc Trop Med Hyg. 2000; 94 (1):9-11. doi: https://doi.org/10.1016/S0035-9203 (00) 90418-8.

2. Black RE, Morris SS, Bryce J. Where and why are 10 million children dying every year? Lancet. 2003; 361 (9376) : 2226-2234. doi: https://doi.org/10.1016/S0140$6736(03) 13779-8$.

3. Pariyo GW, Gouws E, Bryce J, Burnham G. Improving facility-based care for the sick children in Uganda: training is not enough. Health Policy Plan. 2005; 20(1): i58-i68. doi: 10.1093/heapol/czi051.

4. Lawn JE, Consensus S, Zupan J. 4 million neonatal deaths: When? Where? Why? Lancet 2005;365 (9462): 891-900. doi: https://doi.org/10.1016/S0140-6736 (05) $71048-5$

5. Fenn B, Kirkwood BR, Popatia Z, et al. Inequities in neonatal survival interventions: evidence from national survey. Arch Dis Child Fetal Neonatal Ed. 2007; 92(5): F361-F366. doi: 10.1136/adc.2006.104836.

6. Integrated Management of Childhood Illness (IMCI). Available at https: //www.who.int/pmnch / media/ publications /aonsection III_5.pdf accessed on 10 June 2019.

7. World Health Organization. World Health Report 1999: making a difference. Geneva; WHO, 1999.

8. Fagbule D, Kalu A. Case management by community health workers of children with acute respiratory infection: Implications for national ARI control programme. J Trop Med Hyg. 1995;98(4):241-224.

9. Lambrechts $\mathrm{T}$, Bryce $\mathrm{J}$, Orinda $\mathrm{V}$. Integrated Management of Childhood Illness: a summary of first experiences. Bull WHO.1999; 77(7):582-594.

10. Patwari AK, Raina N. Integrated Management of Childhood Illness (IMCI): A Robust Strategy. Indian J Pediatr. 2002; 69:41-48. doi: https:// doi.org/10.1007/ BF02723776. 
Original Research Article

11. Pelletier DL, Frongillo EA, Schroeder DG, Habicht JP. The effects of malnutrition on child mortality in developing countries. Bull WHO. 1995;73(4):443-448.

12. Shah D, Sachdev HPS. Evaluation of WHO / UNICEF algorithm for integrated management of childhood illnesses between the age of two months to five years. Indian Pediatr. 1999;36:767-777.

13. Gupta R, Sachdev HPS, Shah D. Evaluation of WHO / UNICEF algorithm for integrated management of childhood illnesses between the age of one week to two months. Indian Pediatr. 2000;37:383-390.

14. Goswami V, Singh V, Dutta AK. Evaluation of simple clinical signs of illness in young infants (0-2 months) and its correlation with WHO IMCI algorithm (7 days-2 months). Indian Pediatr. 2006;43:1042-1049.

15. World Health Organization. Integrated management of sick child. Bull WHO.1995;73(6):735-740.

16. Gove S. Integrated management of childhood illness by outpatient health worker. Technical basis and overview. Bull WHO. 1997:75(1):7-24.
17. What is Integrated Management of Childhood Illness (IMCI)? Available at https://www.who.int/ maternal_ child_adolescent/child/imci/background/en/ accessed on 9 June 2019.

18. Kaur S, Singh V, Dutta AK, Chandra J. Validation of IMNCI algorithm for young infants (0-2 months) in India. Indian Pediatr. 2011;48(12):955-960. Epub 2011 Mar 15. doi: 10.1007/s13312-011-0155-1.

19. Bhattacharyya A, Saha SK, Ghosh P, Chatterjee C, Dasgupta S. Study comparing the management decisions by IMNCI algorithm and pediatricians in a teaching hospital for the young infants between 0 to 2 months. Ind J Public Health. 2011; 55(4):324-328. doi: 10.4103/0019557X. 92418

20. Thummakomma M, Ramesh P, Reddy M, Balram B. Utility of implementing integrated management of neonatal and childhood illness (IMNCI) algorithm in a tertiary care hospital for the young infants of age 0-2 months. J Evid Med Healthcare. 2016; 3(89): 4868-4872. doi : $10.18410 / \mathrm{jebmh} / 2016 / 1026$.

\section{How to cite this article?}

Bansal R, Sharma R.K, Nayak M, Firoz S.A comparative study to evaluate diagnostic agreement of IMNCI algorithm in young infants. Int J Pediatr Res.2019;6(12): 596-601.doi:10.17511/ijpr.2019.112.02 